\title{
Effectiveness of farmland transfer in alleviating farmland abandonment in mountain regions
}

\author{
SHAO Jing'an ${ }^{1,2}$, ZHANG Shichao $^{1,2}$, LI Xiubin $^{3}$ \\ 1. College of Geography and Tourism, Chongqing Normal University, Chongqing 400047, China; \\ 2. Key Laboratory of Surface Process and Environment Remote Sensing in the Three Gorges Reservoir Area, \\ Chongqing 400047, China; \\ 3. Institute of Geographic Sciences and Natural Resources Research, CAS, Beijing 100101, China
}

\begin{abstract}
Farmland abandonment is a type of land use change in the mountain region, and this change is under rapid development. Whether farmland transfer can prevent this process and promote the effective allocation of land resources or not is a question worth studying and discussion. With the help of the previous research findings, the objective of this paper was to find out the role of farmland transfer on preventing farmland abandonment, by using the methods of multiple view with two factors, and single factor correlation analysis. The results showed that: (1) At village level, a significant negative correlation between farmland transfer and farmland abandonment existed in the study site, with $R^{2}=0.7584$. This correlation of farmland with high grade farming conditions presented more outstandingly. The fitted curve for the farmland at Level I had the largest $R^{2}$ at 0.288 , while that for the farmland at Level IV had the smallest $R^{2}$ at 0.103 . Which indicated that farmland transfer could prevent the abandonment of farmland with high grade farming conditions? (2) At plot level, the abandonment rate of farmland with high grade farming conditions was significantly lower than that of farmland with poor grade farming conditions. It was the lowest at $10.49 \%$ for the farmland with Level I farming conditions, whereas the farmland with Level I farming conditions was $26.21 \%$. Abandoned farmland was mainly contributed by farmland with Level IV farming conditions in the study site. (3) At village level, the role of farming conditions on farmland abandonment was insignificant. The univariate correlation analysis revealed that the abandonment ratio was negatively correlated with the proportions of farmland at Levels I and II and their accumulated proportion; however, their $R^{2}$ were small at 0.194 , 0.258 , and 0.275 , respectively. The abandonment of farmland with high farming conditions still existed. The abandonment ratios of farmland at Levels I and II were high at $9.96 \%$ and $10.60 \%$, respectively. This presented that farmland transfer on behalf of the land rental market was still not developed. (4) However, the village possessed the high rate of farmland transfer, and its rate of farmland abandonment with high grade farming conditions was all lower. When the transfer ratios of farmland were over $20 \%$, the abandonment ratios of farmland at Levels I and II were $6.47 \%$ and $6.92 \%$, respectively. Farmland abandonment was still controlled by the improvement of land rental market. And the functions of land rental market optimizing the utilization
\end{abstract}

Received: 2015-06-18 Accepted: 2015-07-20

Foundation: Funds for International Cooperation and Exchange of National Natural Science Foundation of China (NSFCIIASA Project), No.41161140352; Humanity and Social Science Youth Foundation of Ministry of Education of China, No.10YJCZH122

Author: Shao Jing'an (1976-), Professor, specialized in regional environment evolution and climate responses. E-mail: shao_ja2003@sohu.com 
of farmland resources have been presented to a certain degree. (5) To further improve the marketing degree of land rental, the probability of farmland abandonment could be reduced. Especially, their function to farmland with high grade farming conditions was very obvious, and could avoid the waste of farmland resources with high grade farming conditions.

Keywords: land rental market; farmland abandonment; farming conditions; farmland resource optimization; mountain region

\section{Introduction}

Large areas of farmland in China's mountainous regions are being left uncultivated (or abandoned), thus marking a new change in the relationship between man and land against the background of rural development and land use transformations. Currently, China's rural regions are undergoing significant transformations in development pattern and land use, as driven by the growing wages of non-agricultural workers as well as the decreasing proportion of agricultural income in the family income (Long et al., 2014; Liu et al., 2014). Due to the rising opportunity cost of engaging in farming, large numbers of young adults in the remote mountainous regions are choosing to instead go into non-agricultural sectors in urban areas. In addition, as the rural labor force continues to dissipate, the social value of using land for agriculture is inevitably reduced, and consequently, considerable arable land is abandoned in the mountainous regions where manual labor is unlikely to be replaced by agricultural machinery. As a result of this changing dynamic, there is an expansion of natural ecological land (Pueyo and Beguería, 2007; Seeborg et al., 2000; Mullan et al., 2011; Hou et al., 2014), also known as "transformation from farmland to forest" (Sluiter and de Jong, 2007; Milenov et al., 2014). This problem will continue to worsen with the further migration of rural labor and the aging of those staying in their villages (Zaragozí et al., 2012; Shao et al., 2014; Zhang et al., 2014; Li et al., 2014). However, with goals of maintaining at least 1.8 billion mu of arable land and ensuring food safety, an important question is posed: how can the waste of farmland resources be reduced, especially those providing good farming conditions? Achieving the farmland preservation goal set by the government is and will be a focus of China's efforts to promote sustainable land use and management as well as farmland preservation in future years.

Passed by the Central Committee at the 18th National Congress of the Communist Party of China, the policy concerning the major issues of the country's rural reform gives priority to the establishment of rural farmland transfer markets with an aim to stimulate the transfer of contracted land management rights. This allows the market to play a role in promoting the efficient allocation of land resources. However, controversy exists over whether the market would positively impact the promotion of efficient allocation of land resources. Deininger and Jin (2005) and Yao (2007) found that the transfer of farmland played an important role in increasing both agricultural productivity and family income. Sklenicka et al. (2014) proposed that letting the land-use right be concentrated to a small number of users was key to the sustainable use of fragmentary farmland in mountain regions. Furthermore, Yu et al. (2013) suggested that the market-oriented allocation of agricultural land was the leading factor in increasing the efficiency of land use. Milenov et al. (2014) and Shao et al. (2007) proved that farmland transfer was conducive to promoting a more efficient use of farmland resources. However, farmers are unlikely to engage themselves in a market-oriented alloca- 
tion of farmland resources due to the limitations of the peasant economy and an incomplete market. Furthermore, Burgess (2001) and Shang and Guo (2010) discovered that the incomplete market, market risk, and an imperfect policy implementation could obstruct the accomplishment of a market-oriented allocation of farmland, whereas Ye et al. (2006) and Guan (2011) thought that a property right system and the transaction cost could easily cause a farmland transfer market to fail.

Thus, a question worth discussing arises: can farmland transfer effectively prevent farmland, especially that with good farming conditions, from being left uncultivated in mountainous regions? In this study, the authors investigate whether the development of a rural land leasing market in a mountainous region could aid in improving the allocation of farmland resources and prevent the waste of favorable farmland, based on the assumptions that the rate of farmland transfer reflects the level of activity in a land leasing market and that farming conditions indicate the local resource endowment. This research is expected to provide a scientific basis for pushing forward the marketization of the rural land leasing sector in China's mountainous regions.

\section{Materials and methods}

\subsection{Regional overview}

Shizhu County (area of $3012.24 \mathrm{~km}^{2}$ ) that is studied in this paper is located in the Wuling mountain region $\left(107^{\circ} 59^{\prime} 22^{\prime \prime}-108^{\circ} 34^{\prime} 45^{\prime \prime} \mathrm{E}, 29^{\circ} 39^{\prime} 29^{\prime \prime}-30^{\circ} 32^{\prime} 45^{\prime \prime} \mathrm{N}\right)$, which lies on the border between Chongqing and Hubei (Figure 1). According to the geomorphic division of Sichuan Province, the sample area is located in the Eastern Sichuan Fold Belt, which is composed of medium mountains from Wushan Mountain to Daloushan Mountain. The

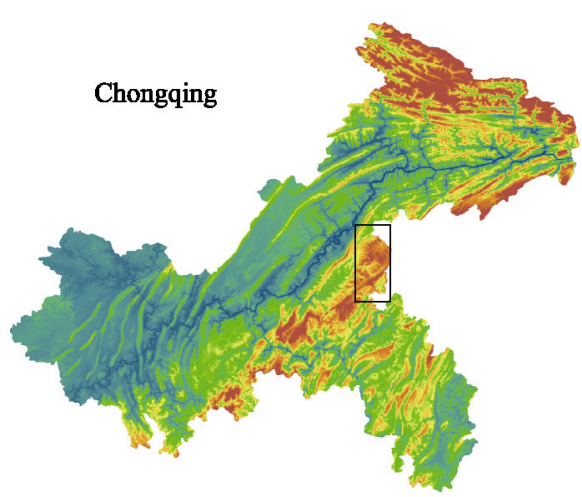

$\operatorname{DEM}(\mathrm{m})$

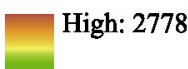

Low: 16

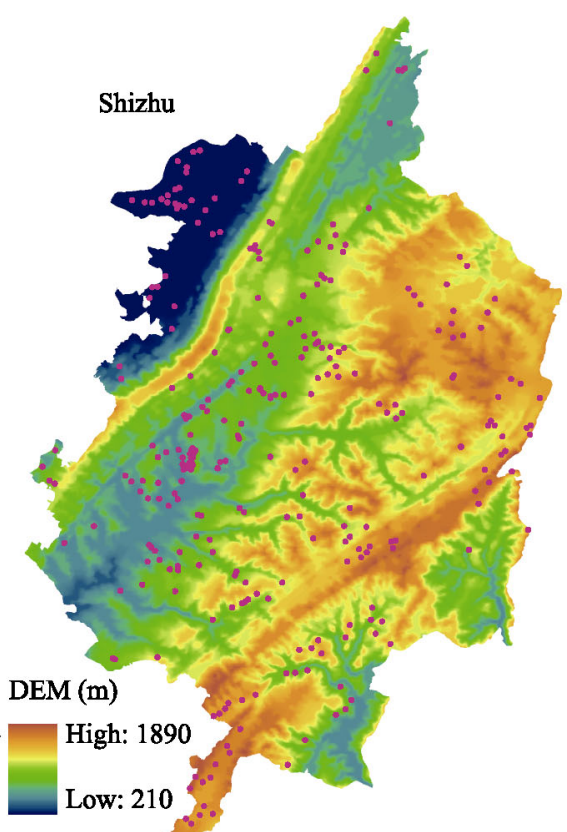

Figure 1 Location of the study site and its topography 
nearly parallel (NE-SW) Qiyue Mountain and Fangdou Mountain, which stretch over the area and have a trough lying in-between, characterize the overall geomorphic features of the area. Medium and low mountains are the main geomorphic units. Additionally, the sample area has a humid subtropical monsoon climate and shows distinctly diversified climatic characteristics. Its annual average temperature is $16.5^{\circ} \mathrm{C}$, and the annual average precipitation is $1103.0 \mathrm{~mm}$. The main soil types include yellow soil, yellow-brown soil, purple soil, and rice paddy soil. Besides the Yangtze River, there are 11 rivers whose drainage areas exceed $100 \mathrm{~km}^{2}$ in this area. The vegetation types include tropical evergreen broadleaf forest and deciduous broadleaf forest, which are mainly composed of Pinus massoniana and firs with a coverage of about $52.8 \%$.

At the end of 2011, a total of 544,500 people lived in the 32 towns and 229 villages of the sample area. The per capita GDP of the area was about 19,400 yuan, and the per capita net income of rural residents was 5,981 yuan. Furthermore, 43.34\% of the local labor force became migrant workers. The decreasing rural labor force has resulted in the transfer of 12239.72 ha of farmland, or $17.14 \%$ of the total area of farmland contracted to the households of the region. A moderate-scale operation was practiced on 17,609.13 ha of farmland (no less than $10 \mathrm{mu}$ per household, $15 \mathrm{mu}=1 \mathrm{ha}$ ), which accounted for $24.66 \%$ of the total area of farmland contracted to households. A farmland transfer and moderate-scale operation have significantly optimized the allocation of farmland resources among different users as well as increased the land utilization rate and productivity per unit of area. Due to the farmland's gradient and distance from settlements in addition to the relative disadvantages of agricultural production, a total of 11575.87 ha of farmland, or $16.18 \%$ of the total area of farmland contracted to local households, remained uncultivated (Shao et al., 2014).

\subsection{Data collection}

The study was conducted on both plot and village scales. On the plot scale, an investigation was carried out into the farming conditions and distribution of farmland, including cultivated land and uncultivated land. The village-scale analysis focused on relationships between farmland transfer, farmland abandonment, and farming conditions. It was necessary to find out whether the differences between village samples in the farmland transfer and abandonment situation were determined by varying farming conditions.

Therefore, data collection was undertaken on both the plot and village scales. On the plot scale, a 1:10,000 farmland distribution map of the sample area (2011) was obtained from the results of interpretation and superposition of the SPOT-5 image (with a resolution of $2.5 \mathrm{~m}$ ), a vector topographic map (2002), and an afforestation distribution map (2002-2008) in previous research (Shao et al., 2014). The rural settlement distribution map and the village-scale administrative map over the same period were acquired from the Land and Resources and the Housing Authority of Shizhu Tujia Autonomous County. Furthermore, DEM data with a 30-m resolution were obtained from the Environmental and Ecological Science Data Center for West China. These images, maps, and data were projected onto the village-scale administrative map in order to obtain data concerning the transferred farmland, uncultivated farmland, and farming conditions of the area.

On the village scale, the transferred farmland areas were obtained mainly through participatory rural appraisals and field surveys, which were carried out by the research team in 
all 32 towns between May $15^{\text {th }}$ and June $3^{\text {rd }}$ in 2014. Moreover, 163 entities involved in farmland transfer were interviewed, including 93 ordinary rural households, 51 large farms, 12 specialized cooperatives, and 7 companies. For each town, the leaders at both the village and town levels were convened by the investigators at the town's government office, and together, they conducted a participatory rural appraisal of transferred farmland areas (2011) by referring to the agricultural economic reports of the villages. Any place with a transferred farmland area of greater than 2.0 ha was plotted on the 1:10,000 farmland distribution map of each village. This process was repeated for all village samples by randomly sampling entities involved in the farmland transfer, such as ordinary rural households, large farms, specialized cooperatives, and companies. To verify and supplement the collected data, field surveys were carried out in some of the regions where the farmland transfer took place, and their GPS coordinates were recorded.

\subsection{Data analysis}

(1) Representation of farming conditions

Previous research results indicated that farming conditions (including the gradient $(G)$ of the farmland plot as well as its distance $(D)$ and altitude difference $(A)$ from the settlement (Figure 2)) are the most important factors affecting the occurrence of farmland abandonment in the sample area, and additionally, there are negative correlations between the three factors and the uncultivated farmland area (Shao et al., 2014). Therefore, the farming conditions can be represented by the product of the three factors: $G \times D \times A$. The larger the three factors are, the larger their product and the worse the farming conditions, and vice versa.

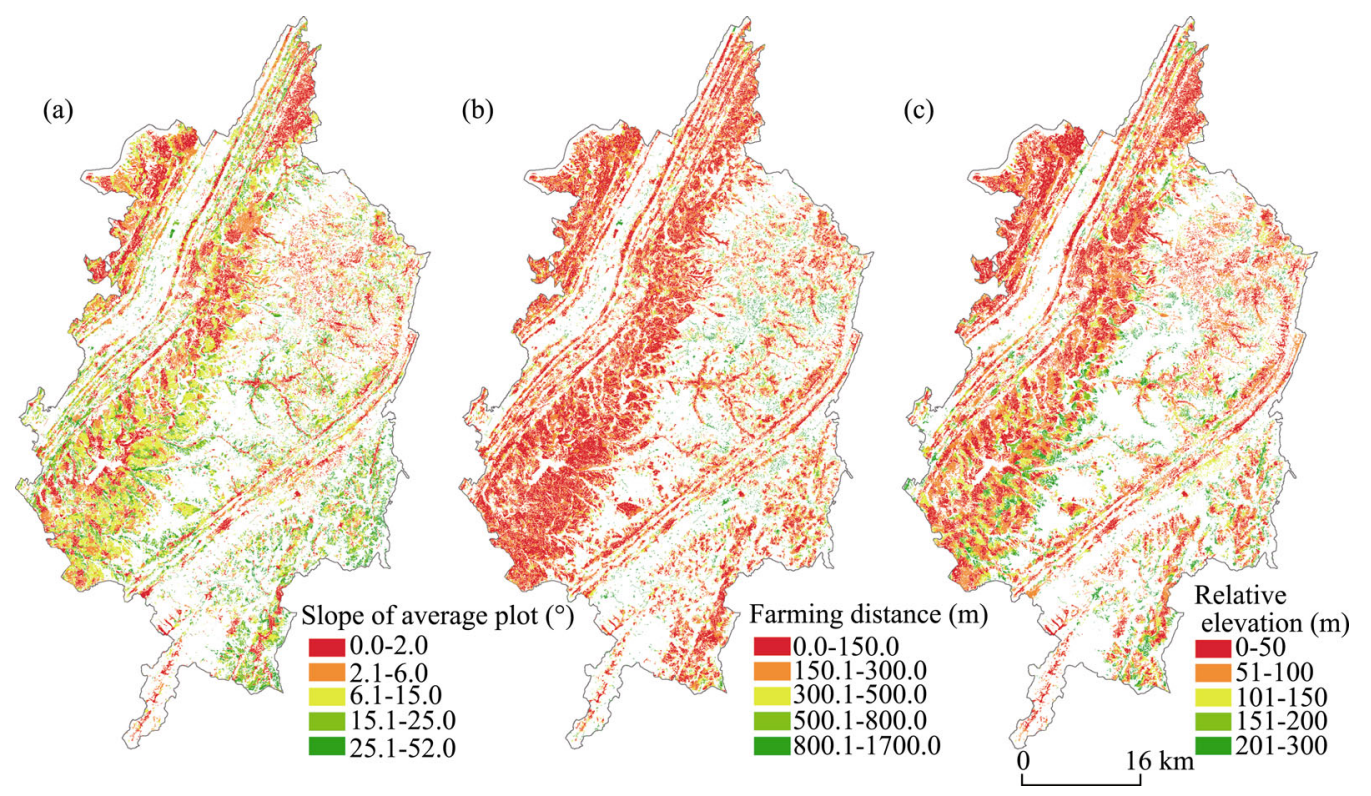

Figure 2 Slope of patch, farming distance of patch, and relative elevation between patch and village

Data concerning the gradient of farmland plots and the topographic position index were obtained from previous research results. The altitude difference between a farmland plot and a settlement was the absolute value of the difference of the plot's centroid altitude and the 
arithmetic mean of the settlements' centroid altitudes. The centroids of the farmland plots and the related settlements were extracted from the DEM, and the altitudes of these centroids were extracted using Extract Value to Points. The arithmetic mean of the altitudes of the settlements' centroids was calculated, and then, it was subtracted from each plot's centroid altitude. The absolute value of the result was the altitude difference between each plot and settlement.

The linear distance from each plot to the settlement nearest to it was extracted from the rural settlement distribution map (2011). Then, the results were corrected by introducing the topographic position index, thereby yielding the corrected distance between each farmland plot and the nearest settlement.

(2) Classification of farming conditions

The farming conditions of the area's farmland were divided into four levels for more easily analyzing their relationships with farmland transfer and abandonment (Figure 5c): higher levels suggest worse farming conditions. Furthermore, anisotropic changes in the farmland's gradient as well as the distance and altitude difference from settlement would affect their product. If any one of them is zero while the other one or two are relatively large, then the product of the three factors could not accurately characterize the farming conditions, thus affecting the classification of farming conditions. This is because the product 0 , which should represent good farming conditions, concealed the harsh farming conditions that were determined by the larger factor(s) according to the bucket theory.

Therefore, the classification method in previous research was used in the study. If a farmland plot satisfied any one of the three following conditions: $G \geqslant 25^{\circ}, D \geqslant 800 \mathrm{~m}$, and $A \geqslant$ $100 \mathrm{~m}$, then its farming conditions were directly classified as Level IV, rather than being represented by the product of the three factors. The three factors of the remaining plots were then standardized according to their correlations with the farming conditions. To avoid the influence of value 0 on the classification of farming conditions, a value of 1 was assigned to any factor equaling 0 prior to the standardization and multiplication operation. The multiplication results were arranged in order from smallest to largest, and together with those classified into Level IV, the results were then divided into four equal portions. In terms of farmland areas, the final classification results were generally consistent with the result in the Agricultural Land Classification in Sizhu County, Chongqing (2008).

(3) Statistical significance of indicators

To investigate the effectiveness of farmland transfer in reducing the farmland abandonment as well as the relationship between farmland abandonment and farming conditions, four indicators were introduced to the study: farmland transfer ratio $\left(R_{1}\right)$, abandonment ratio $\left(R_{2}\right)$, abandonment ratio of each farming conditions level $\left(R_{3}\right)$, and proportion of farmland at each farming conditions level. According to previous research results and the distribution patterns of the two ratios in the village samples, both the farmland transfer ratios and abandonment ratios were split into three intervals: $R_{1}, R_{2} \leqslant 10 \%, 10 \%<R_{1}, R_{2}<20 \%$, and $R_{1}, R_{2}$ $\geqslant 20 \%$. Then, the areas of transferred farmland and uncultivated farmland at each level of farming conditions were estimated for each village sample.

The overall abandonment ratio $R_{2}$ and the overall transfer ratio $R_{1}$ of a village were respectively the ratios of the area of uncultivated farmland and that of transferred farmland to the total farmland area in the village. The abandonment ratio of each farming conditions 
level was the ratio of the area of uncultivated farmland at each level to the total farmland area in each village. The proportion of farmland at each level was the result of dividing the area of uncultivated farmland at each level by the total farmland area in each village. The abandonment ratio of a village in an $R_{1}$ interval was the ratio of the area of uncultivated farmland at a level to the total area of farmland at this level in the village. For a village, the proportion of farmland at each level in an $R_{1}$ or $R_{2}$ interval was the result of dividing the area of farmland at each level in the village by the village's total farmland area.

The relationships between these indicators were analyzed through three types of statistical analyses: (1) a statistical analysis of both the abandonment ratios (including the overall abandonment ratio and the abandonment ratios of different levels) and the transfer ratios was conducted in order to explain the relationship between the transfer ratio and abandonment ratio with an aim to determine the relationship between farmland transfer and abandonment in terms of the overall situation and resource endowment; (2) the relationship between the abandonment ratio and resource endowment was interpreted by analyzing the abandonment ratios of different levels and the statistical relationship between the proportions of farmland at different levels and abandonment ratios with an aim to discover if the abandonment ratio depends on the resource endowment; and finally, (3) a statistical analysis of the proportions of farmland with different farming conditions and the transfer ratios depicted the relationship between the transfer ratio and resource endowment with an aim to find out whether the transfer ratios in regions with good farming conditions were higher than those in regions with poor farming conditions.

(4) Statistical methods

Scatter plots with two variables were used to analyze the relationships between land abandonment and transfer, between the abandonment ratio of each level and the transfer ratio, between the abandonment ratio and proportion of farmland at each level, and between the transfer ratio and proportion of farmland at each level.

A univariate correlation analysis was used to determine accurate correlations between different variables. In analyzing the correlation between the farmland abandonment ratio and transfer ratio, the transfer ratio was a dependent variable, and each level's abandonment ratio was an independent variable. When analyzing the correlations between the abandonment and transfer of farmland and farming conditions, the abandonment ratio and transfer ratio were dependent variables, while the proportion of farmland at each level was an independent variable.

\section{Results and discussion}

\subsection{Did the occurrence of farmland abandonment depend on the farming conditions?}

The transfer of farmland in a mountain region was strongly negatively correlated with farmland abandonment. In the sample area, the univariate correlation analysis suggested a relatively strong negative correlation between the transfer ratio and abandonment ratio, with $R^{2}$ $=0.595$ (Table 1). The significance test with a significance level of 0.01 demonstrated that the result was statistically significant. Furthermore, in the scatter plot (Figure 3 ), the $R^{2}$ of the exponential trend line was 0.7584 , thus indicating that the transfer ratio and abandonment ratio were strongly correlated. In terms of spatial distribution, the transfer ratio and 
Table 1 A single correlation between farmland abandonment ratio, farmland transfer ratio and the proportion of farmland of each level farming condition

\begin{tabular}{|c|c|c|c|c|c|c|c|c|}
\hline \multirow{2}{*}{\multicolumn{2}{|c|}{ Correlation analysis }} & \multirow{2}{*}{$R^{2}$} & \multicolumn{2}{|c|}{$\begin{array}{l}\text { Unstandardized } \\
\text { coefficients }\end{array}$} & \multirow{2}{*}{$\begin{array}{c}\text { Stan- } \\
\text { dard } \\
\text { coeffi- } \\
\text { cient }\end{array}$} & \multirow{2}{*}{$t$} & \multirow{2}{*}{ Sig. } & \multirow{2}{*}{$F$} \\
\hline & & & B & $\begin{array}{l}\text { Standard } \\
\text { error }\end{array}$ & & & & \\
\hline \multicolumn{2}{|c|}{$\begin{array}{l}\text { Farmland abandonment ratio and } \\
\text { transfer ratio }\end{array}$} & 0.595 & -1.172 & 0.064 & -0.772 & -18.272 & $0.000^{* * *}$ & 333.852 \\
\hline \multirow{5}{*}{$\begin{array}{l}\text { Farmland abandonment } \\
\text { ratio and the proportion } \\
\text { of farmland of each } \\
\text { level farming condition }\end{array}$} & Level I & 0.194 & -0.319 & 0.043 & -0.441 & -7.398 & $0.000^{* * *}$ & 54.736 \\
\hline & Level II & 0.258 & -0.358 & 0.04 & -0.508 & -8.875 & $0.000^{* * *}$ & 78.769 \\
\hline & Levels I and II & 0.275 & -0.206 & 0.022 & -0.524 & -9.268 & $0.000^{* * *}$ & 85.901 \\
\hline & Level III & 0.014 & 0.094 & 0.053 & 0.118 & 1.786 & $0.075^{*}$ & 3.191 \\
\hline & Level IV & 0.303 & 0.256 & 0.026 & 0.551 & 9.937 & $0.000^{* * *}$ & 98.748 \\
\hline \multirow{5}{*}{$\begin{array}{l}\text { Farmland transfer ratio } \\
\text { and abandonment ratio } \\
\text { of each level farming } \\
\text { condition }\end{array}$} & Level I & 0.288 & -0.337 & 0.035 & -0.537 & -9.589 & $0.000^{* * *}$ & 91.941 \\
\hline & Level II & 0.258 & -0.223 & 0.025 & -0.508 & -8.875 & $0.000^{* * *}$ & 78.769 \\
\hline & Levels I and II & 0.376 & -0.187 & 0.016 & -0.613 & -11.705 & $0.000^{* * *}$ & 136.997 \\
\hline & Level III & 0.19 & -0.211 & 0.029 & -0.436 & -7.308 & $0.000^{* * *}$ & 53.4 \\
\hline & Level IV & 0.103 & -0.114 & 0.022 & -0.321 & -5.104 & $0.000^{* * *}$ & 26.049 \\
\hline \multirow{5}{*}{$\begin{array}{l}\text { Farmland transfer ratio } \\
\text { and the proportion of } \\
\text { farmland of each level } \\
\text { farming condition }\end{array}$} & Level I & 0.186 & 0.205 & 0.028 & 0.431 & 7.202 & $0.000^{* * *}$ & 51.871 \\
\hline & Level II & 0.302 & 0.255 & 0.026 & 0.55 & 9.918 & $0.000^{* * *}$ & 98.363 \\
\hline & Levels I and II & 0.294 & 0.141 & 0.014 & 0.542 & 9.728 & $0.000^{* * *}$ & 94.631 \\
\hline & Level III & 0.036 & -0.099 & 0.034 & -0.189 & -2.893 & $0.004^{* *}$ & 8.368 \\
\hline & Level IV & 0.282 & -0.163 & 0.017 & -0.531 & -9.444 & $0.000^{* * *}$ & 89.196 \\
\hline
\end{tabular}

Note: $* * *, * *$ and $*$ indicated that there was significant correlation between two variables at the level of $0.01,0.05$ and 0.1 .

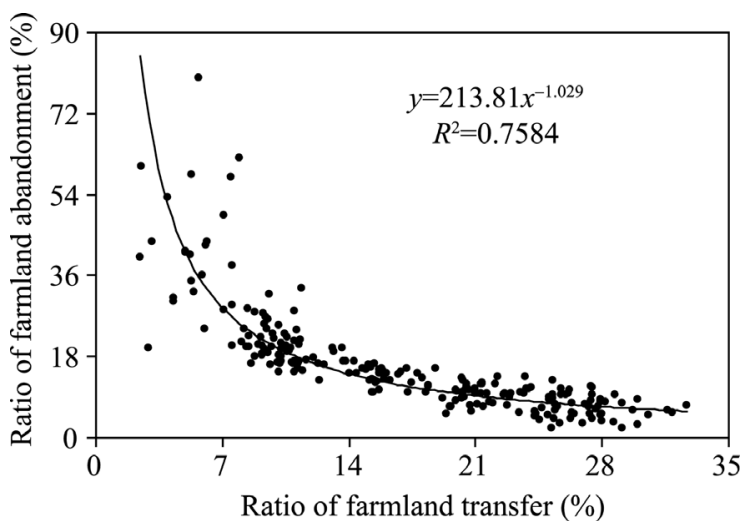

Figure 3 The relationships between ratio of farmland transfer and ratio of farmland abandonment abandonment ratio showed relatively significant negative correlation (Figures $5 \mathrm{a}$ and $5 \mathrm{~b}$ ). These findings demonstrate that there was a significant negative correlation between the transfer ratio and abandonment ratio, and the abandonment ratios were low in villages with high transfer ratios, which is consistent with the conclusions of previous research. However, the simple correlation analysis is insufficient for leading to the conclusion that the transfer of farmland in mountainous regions can help prevent farmland from being left uncultivated.

This is because in a well-established land leasing market, farmland with good farming conditions is more likely to be used, rather than being abandoned, due to its high productivity. The villages exhibiting low abandonment ratios may have extensive farmland with good farming conditions. Therefore, it was necessary to determine whether the differences in the abandonment ratios between villages were determined by varying farming conditions. 
On the plot scale, the abandonment ratios of farmland with favorable farming conditions were significantly lower than those of inferior farmland. The abandonment ratio of the farmland with Level IV farming conditions was $26.21 \%$, which was the highest among all types of farmland, whereas the farmland with Level I farming conditions was the lowest at 10.49\% (Figures 4, 5a and 5c). Though the abandonment ratios increased as the farming conditions declined from Level I to Level III, they were still smaller than

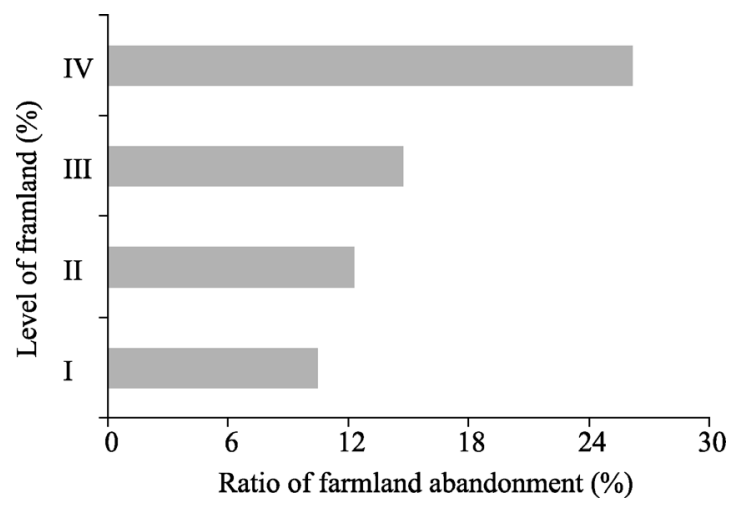

Figure 4 The ratio of farmland abandonment under each level farming condition the overall abandonment ratio of the sample area (16.18\%), thus indicating that the farmland with Level IV farming conditions contributed most to the overall abandonment ratio.

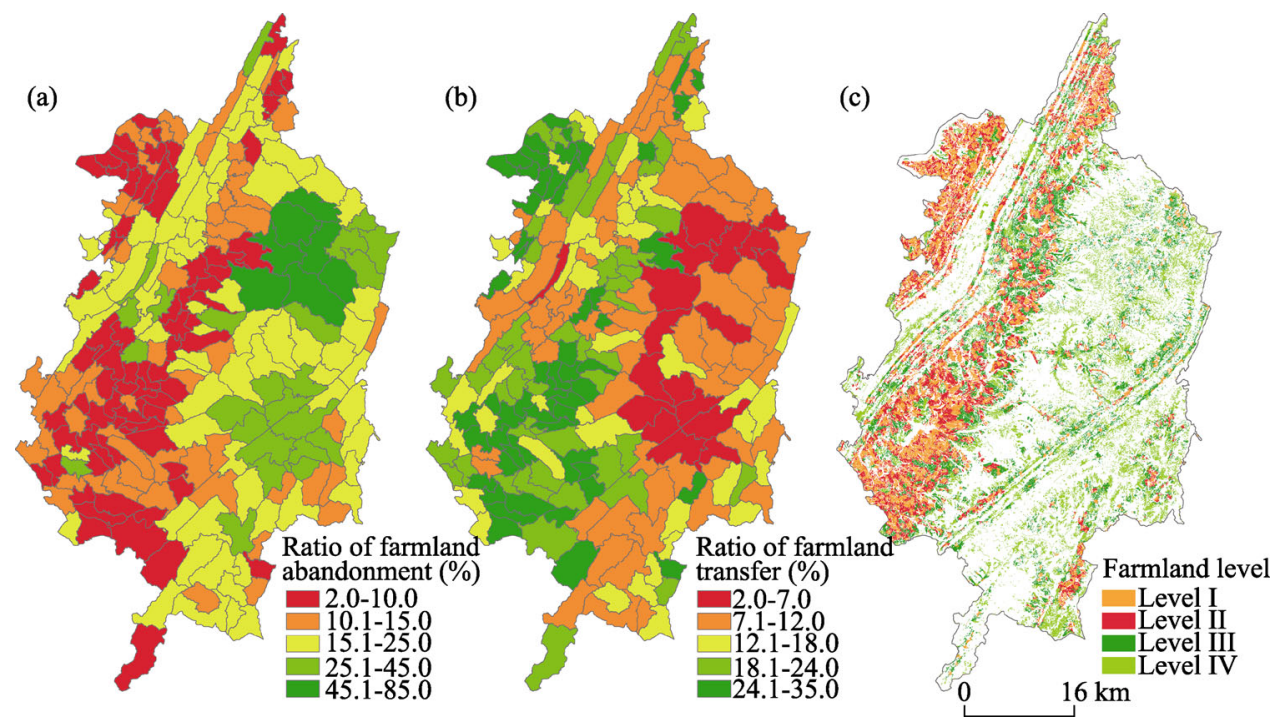

Figure 5 The spatial distributions of farmland abandonment ratio, farmland transfer ratio and framing conditions

As shown in Figure 6, the farmland at Levels I and II accounted for $66.77 \%$ of the farmland whose abandonment ratios were smaller than $10 \%$, which is higher than the proportions of farmland at the other two levels in this interval. The farmland at Level IV was $46.64 \%$ of the farmland whose abandonment ratios were larger than $20 \%$, the highest proportion in this interval. These findings are consistent with previous research and field survey results that found that the abandonment ratio of a farmland increased with increasing gradient as well as

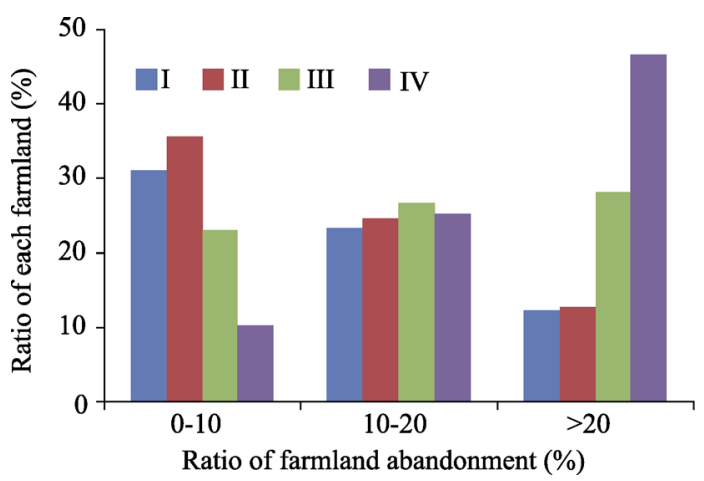

Figure 6 The proportion of farmland of each level farming condition under different ranges of farmland abandonment ratio 


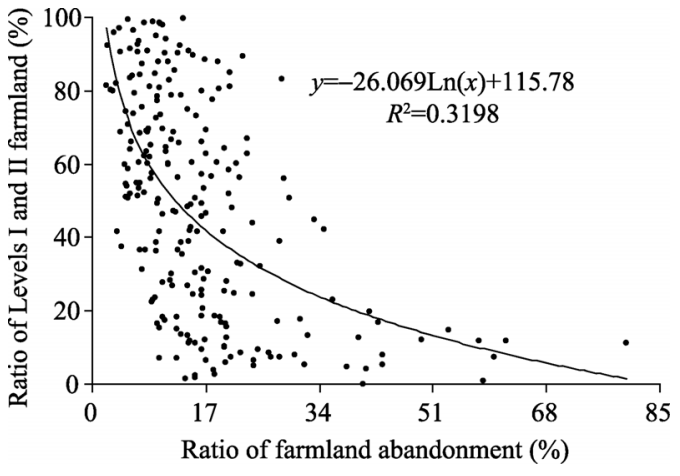

Figure 7 The relationships between the proportion of farmland of Levels I and II farming conditions and farmland abandonment ratio

increasing distance and altitude difference from a settlement. However, interestingly, among the farmland with abandonment ratios between $10 \%$ and $20 \%$, the proportions of farmland with different farming conditions varied slightly, ranging from $23 \%$ to $25 \%$, with little variation from level to level. This demonstrates that farmlands that were favorable for agricultural production were also abandoned. Moreover, the farmland with Level III farming conditions was relatively evenly distributed in different intervals of abandonment ratio. This was because Level III was the critical level of farming conditions for the agricultural production in this area. If a plot of farmland can provide better farming conditions, then it is productive and will likely to be used for agricultural production; otherwise, it will likely remain uncultivated.
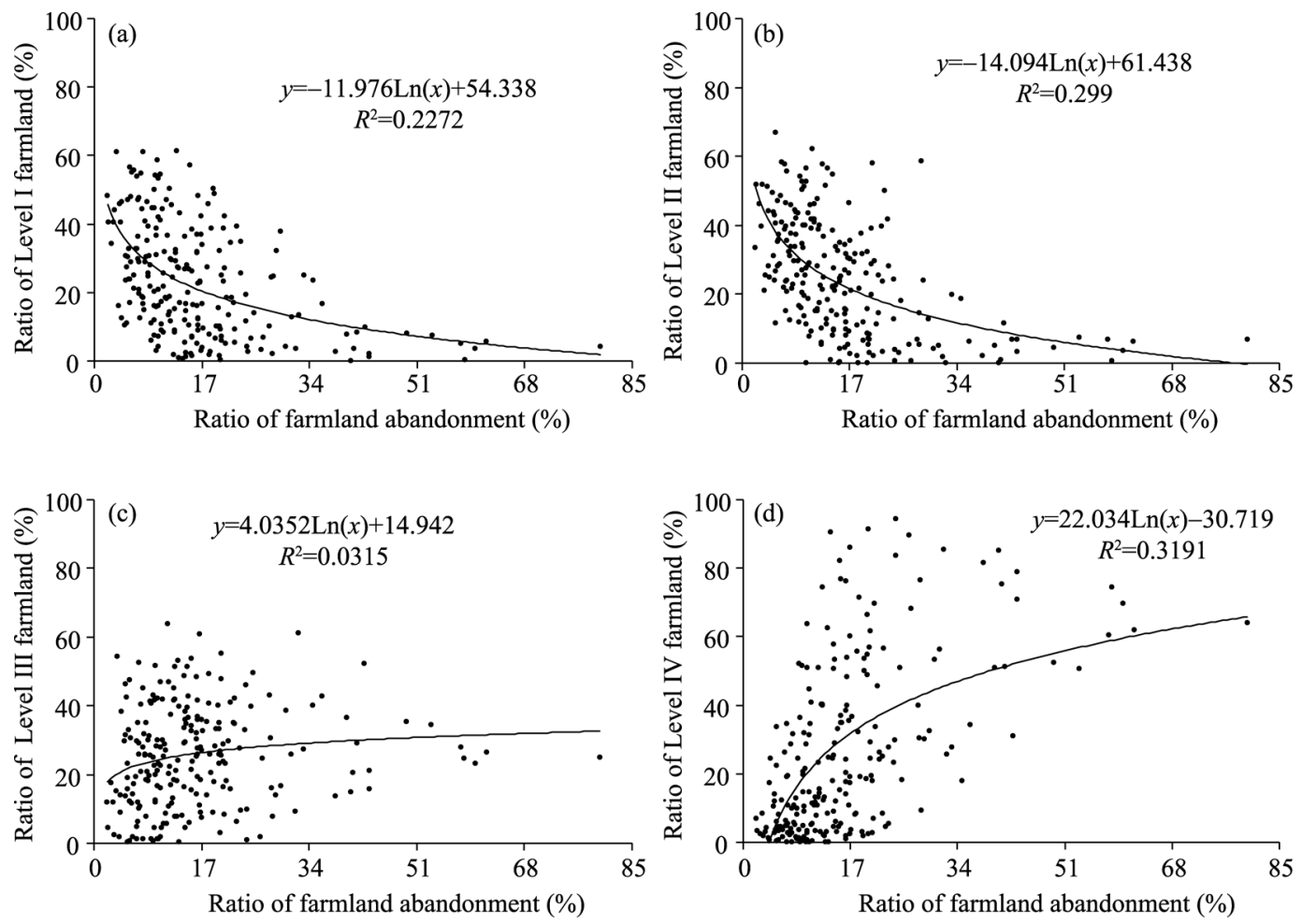

Figure 8 The relationships between proportion of farmland of each level farming condition and farmland abandonment ratio

On the village scale, the correlation between the farming conditions and abandonment ratio was relatively weak in the mountainous regions. The univariate correlation analysis revealed that the abandonment ratio was negatively correlated with the proportions of farm- 
land at Levels I and II and their accumulated proportion (a significance test with a significance level of 0.01 demonstrated that the result attained statistical significance); however, their $R^{2}$ were small at $0.194,0.258$, and 0.275 , respectively (see Table 1 ). In addition, the scatter plots in Figures 7 and 8 also show negative correlations between the aforementioned relationships, and the $R^{2}$ of the fitted logarithmic curves were also small. This suggested that the differences in the abandonment ratios of different villages could not be completely attributed to the varying farming conditions. Normally, in a well-established land leasing market, farmland with good farming conditions tends to be used rather than abandoned. In the sample area, however, the abandonment ratios of farmland at Levels I and II were high at $9.96 \%$ and $10.60 \%$, respectively, thus implying that some farmland with good farming conditions was also left uncultivated.

In accordance with the principle of a market-oriented allocation of resources and with the land rent theory, farmland with good farming conditions has relatively high economic value and is, thus, supposed to be used, and in contrast, that with poor farming conditions is more likely to be left uncultivated if the local land leasing market is well established. Thus, the abandonment of farmland with good farming conditions in this area indicates that the land leasing market is too incomplete to promote the reuse of the uncultivated farmland with good farming conditions. Therefore, it can be concluded that the continued progress of marketization will be important for reducing the occurrence of farmland abandonment in the sample area.

\subsection{Could the farmland transfer help reduce the occurrence of farmland abandon- ment?}

The negative correlation between the abandonment ratio and transfer ratio was strong among the farmland with good conditions in the mountainous region. Though the transfer ratios and abandonment ratios of different levels were negatively correlated in all villages, as was indicated by the univariate correlation, the relationship was more statistically significant among the farmland with better farming conditions. The fitted curve for the farmland at Level I had the largest $R^{2}$ at 0.288 , while that for the farmland at Level IV had the smallest $R^{2}$ at 0.103 . The accumulated $R^{2}$ for the farmland at Levels I and II was 0.376. In terms of spatial distribution, the abandonment ratio, transfer ratio, and farming conditions also display distinct relationships (Figure 5). In addition, the scatter plots in Figures 9 and 10 exhibit the same characteristics. A higher transfer ratio tends to result in a lower abandonment ratio, and this trend was especially remarkable for the farmland with good farming conditions.

Figure 11 shows that when $R_{1}<10 \%$, the abandonment ratio of each level was greater than $20 \%$, which is higher than the overall abandonment ratio of the sample area $(16.18 \%)$. Furthermore, the abandonment ratios of Levels III and IV were high at $30.77 \%$ and $42.79 \%$, respectively. In the other two intervals, the abandonment ratios sharply declined. When $R_{1}>$ $20 \%$, the abandonment ratios declined by $67.01 \%-70.83 \%$ to the levels below $15 \%$, which is lower than the overall abandonment ratio of the sample area. Among the farmlands at Levels I and II, the abandonment ratios varied slightly from interval to interval. Moreover, the abandonment ratio of Level III was closer to the abandonment ratios of the two lower levels than to that of Level IV, thus suggesting that the transfer of farmland was effective in controlling the abandonment of farmland with good or moderate farming conditions. 

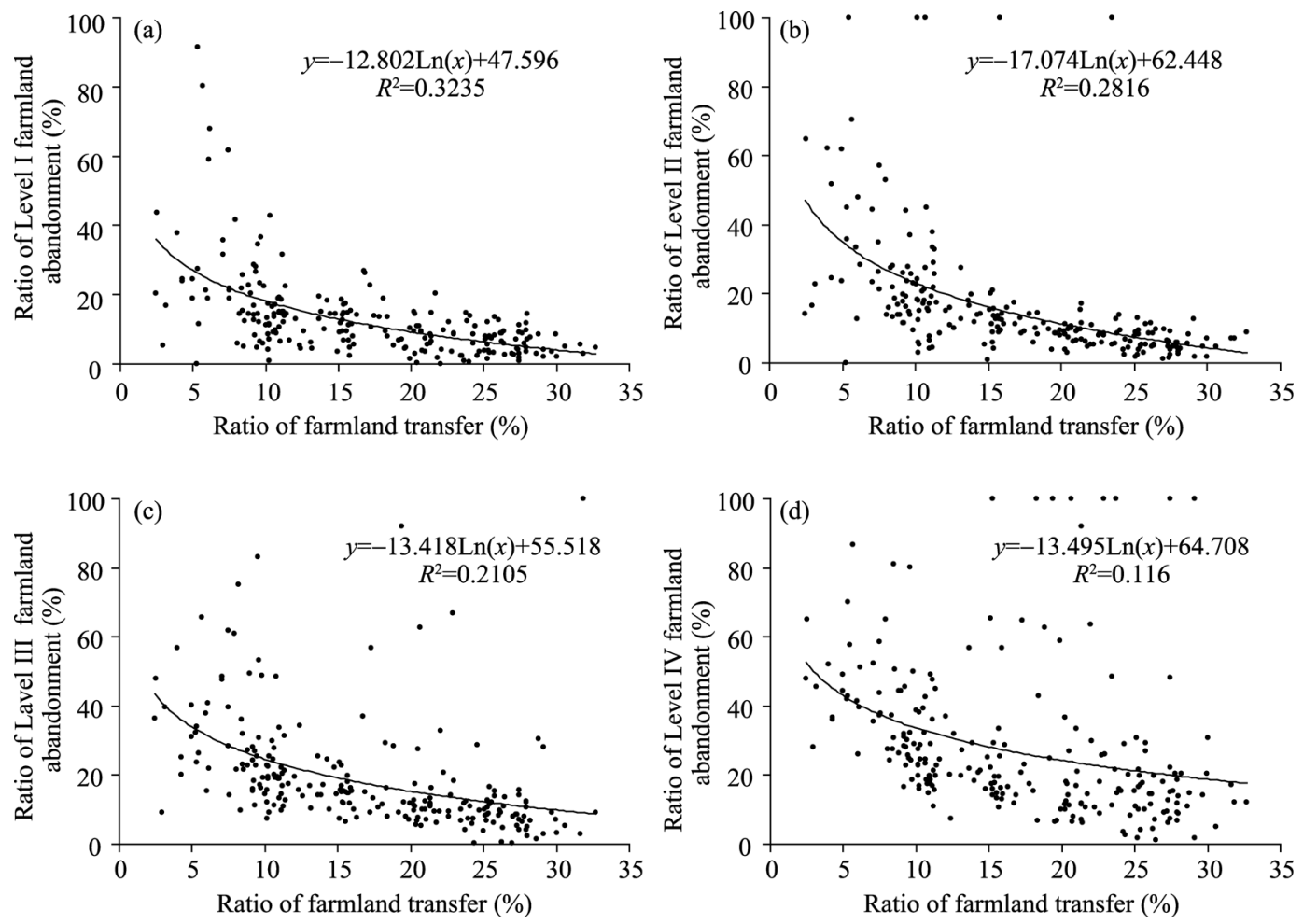

Figure 9 The relationships between ratio of farmland transfer and ratio of farmland abandonment under each level farming condition
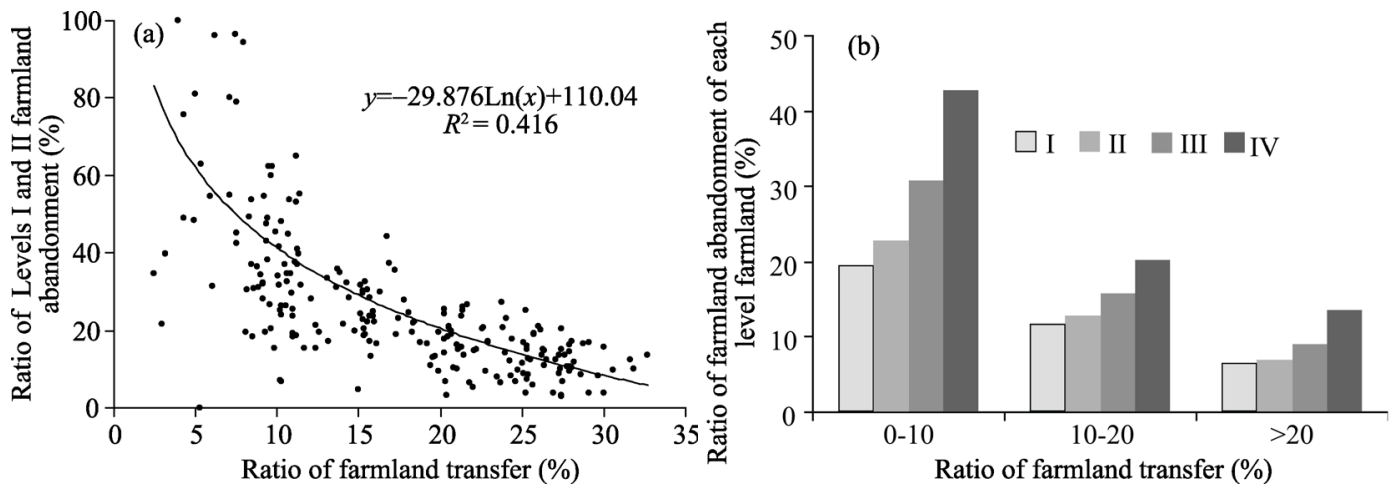

Figure 10 The relationships between ratio of farmland transfer and ratio of farmland abandonment under Levels I and II farming conditions

Another similar question that needs to be addressed is whether the occurrence of farmland transfer was determined by farming conditions. In a complete land leasing market, the transfer ratios of farmland with good farming conditions, which is more productive land, are supposed to be higher than those of farmland with poor farming conditions. As shown in Figure 12, when $R_{1}<10 \%$, the proportion of the farmland at Level IV was $45.16 \%$, which is the largest among the farmland in this interval, and the accumulated proportion of the farmland at Levels I and II was $27.49 \%$, similar to that of the farmland at Level III. When $R_{1}>$ $20 \%$, the accumulated proportion of farmland at Levels I and II was $63.60 \%$, and the farmland at Level IV accounted for the smallest proportion at $12.67 \%$ of the farmland in this in- 
terval. This result indicates that if there is a land leasing market, then the farmland with good farming conditions is likely to be transferred and used despite its higher rental since it is distinctly advantageous for agricultural production. The transfer of land management rights can help lower the probability of farmland abandonment and optimize the allocation of resources.

The characteristics of proportions of farmland in different intervals of the transfer ratio were similar to those in different intervals of the abandonment ratio. When the transfer ratio was between $10 \%$ and $20 \%$, there was little variation in the proportions of farmland at different levels (22\%-28\%), indicating that the transfer ratio was not completely determined by the level of farming conditions. Moreover, the proportions of farmland at Level III in the three transfer ratio intervals were between $23 \%$ and $27 \%$ with there being little variation from interval to interval. This suggests that Level III was the critical level of farming conditions that governed the reuse and reallocation of farmland resources and was the lowest level that the land leasing market could affect. Accordingly, farmland with farming conditions poorer than this level was unlikely to be transferred.

On the village scale, the farming conditions' effect on the transfer ratio did not vary much from village to village. The villages providing favorable farming conditions exhibited slightly higher transfer ratios, thereby implying that the farming conditions' influence on the transfer ratios in different villages was statistically insignificant (Table 1). Therefore, their higher transfer ratios were not attributed to larger proportions of farmland with good farming conditions. The univariate correlation analysis indicated that the proportions of farmland at Levels I and II and their accumulated proportion were positively correlated with the transfer ratio, and in contrast, the proportion of farmland at Level IV was

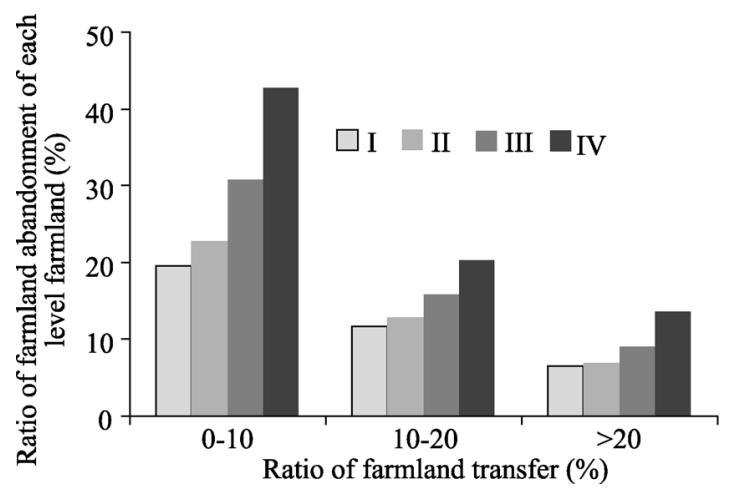

Figure 11 The ratio of farmland abandonment of each level farming condition under different ranges of farmland transfer ratio

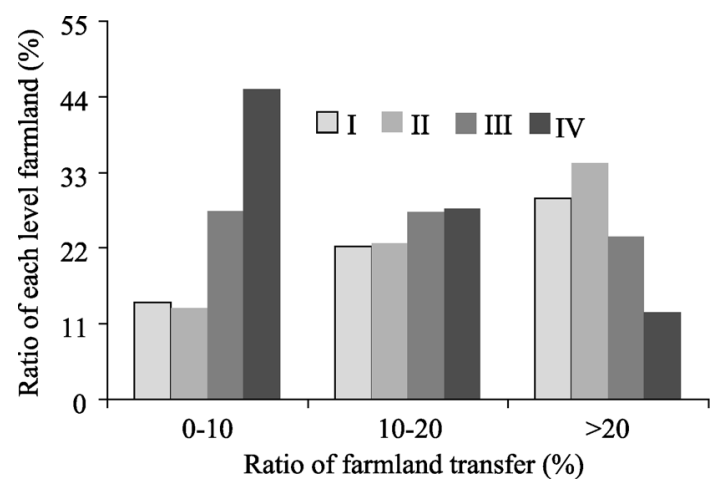

Figure 12 The proportion of farmland of each level farming condition under different ranges of farmland transfer ratio

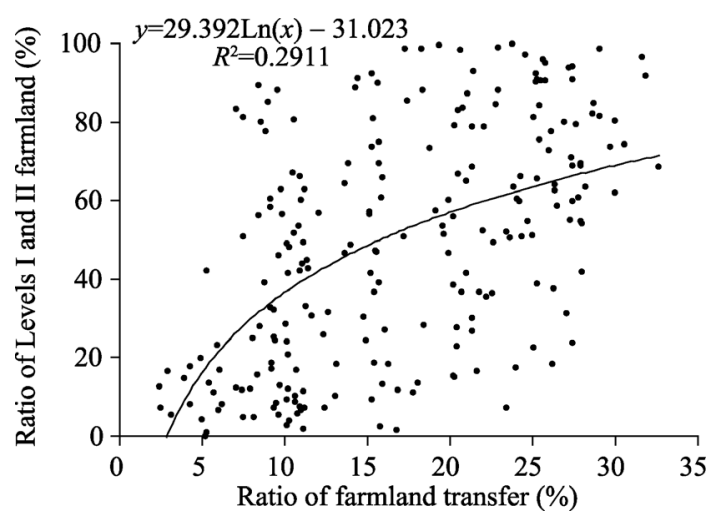

Figure 13 The relationships between the proportion of farmland of Levels I and II farming conditions and farmland transfer ratio 
negatively correlated with the transfer ratio, but their $R^{2}$ were small at just $0.186,0.302$, 0.294, and 0.282, respectively. In addition, the clutter plots in Figures 13 and 14 exhibit similar characteristics. These observations imply that the farming conditions do not fully account for the variation in the transfer ratio between villages, and in addition, they were not the major factor determining the occurrence of farmland transfer in the mountainous regions. Therefore, it has been concluded that the transfer ratio is not determined solely by farming conditions.
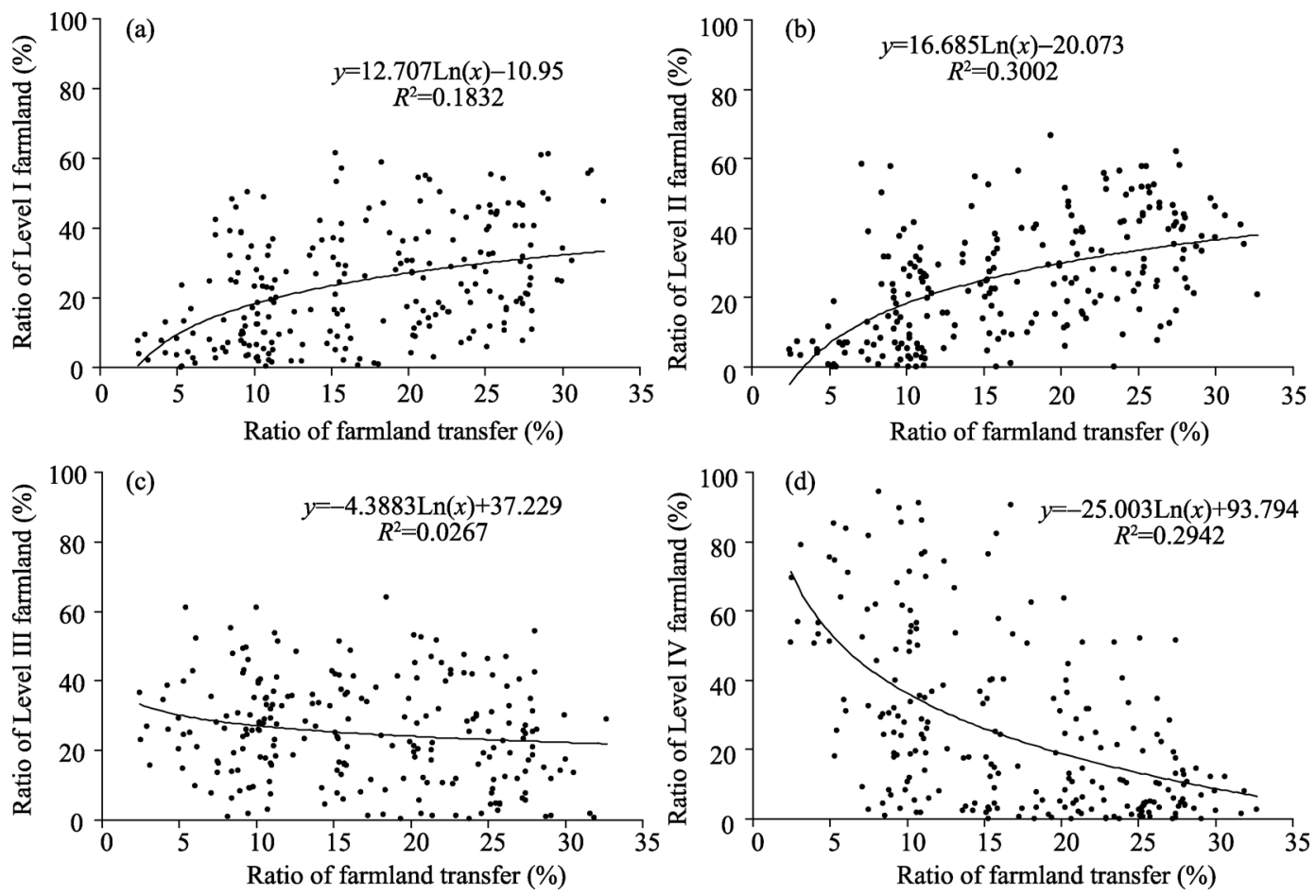

Figure 14 The relationships between the proportion of farmland of each level farming condition and farmland transfer ratio

The differences in the transfer ratio between villages did not vary much with the farming conditions, thus indicating that the land leasing market in the sample area was too immature to optimize the allocation of farmland resources. Therefore, the progress of marketization continues to greatly affect the occurrence of farmland transfer.

In the sample area, the abandonment ratio of the farmland with good farming conditions, especially the Levels I and II farming conditions, was strongly negatively correlated with the transfer ratio. In the villages with high transfer ratios, the abandonment ratios of farmland with good farming conditions were relatively low and decreased with the transfer ratio. This demonstrates that the land leasing market had some effect in increasing the utilization rate of farmland resources. Thus, it has been concluded that a more developed land leasing market will play a greater role in reducing farmland abandonment, especially farmland with good farming conditions, thus preventing the waste of favorable farmland resources. However, the market was still ineffective for preventing farmland with poor farming conditions from remaining uncultivated. The inferior farmland is being abandoned as a result of the farmland's low productivity in addition to the costly expenses of using it for agricultural production. 
Previous research has concluded that the abandonment of inferior farmland by the market is conducive to the restoration of the degraded farmland and the ecological integrity in mountainous regions. In a larger sense, since the occurrence of farmland abandonment is affected by the progress of marketization, furthering the marketization of the land leasing sector will help achieve a more reasonable allocation of farmland resources.

\section{Conclusions}

(1) There was a strong negative correlation between the transfer ratio and the abandonment ratio of farmland in the sample area, with $R^{2}=0.7584$. Higher transfer ratios resulted in lower abandonment ratios. At the plot level, the farmland with good farming conditions had distinct advantages over the farmland with poor farming conditions and exhibited much lower abandonment ratios. The abandonment ratio of the farmland with Level IV farming conditions was $26.21 \%$, whereas the farmland with Level I farming conditions was the lowest at $10.49 \%$. At the village level, the correlation between the farming conditions and abandonment ratio was relatively weak. Farmlands with good farming conditions were also abandoned. The abandonment ratios of farmland at Levels I and II were high at $9.96 \%$ and $10.60 \%$, respectively.

(2) The negative correlation between the abandonment ratio and the transfer ratio was especially strong among the farmland with good conditions. The farmland transfer was found to be effective in reducing the abandonment of farmland with good or moderate farming conditions. The fitted curve for the farmland at Level I had the largest $R^{2}$ at 0.288 , while that for the farmland at Level IV had the smallest $R^{2}$ at 0.103 . The villages providing favorable farming conditions exhibited slightly higher transfer ratios, thus implying that farming conditions' influence on the transfer ratios in different villages was statistically insignificant. The univariate correlation analysis indicated that the proportions of farmland at Levels I and II were positively correlated with the transfer ratio, but their $R^{2}$ were small at just 0.186 and 0.302 , respectively.

(3) The farming conditions' effect on the abandonment ratio did not vary much from village to village. The univariate correlation analysis revealed that the abandonment ratio was negatively correlated with the proportions of farmland at Levels I and II and their accumulated proportion; however, their $R^{2}$ were small at $0.194,0.258$, and 0.275 , respectively. Thereby this indicating that the land leasing market dominated by farmland transfer was still undeveloped. The abandonment ratio of the farmland with good farming conditions was strongly negatively correlated with the transfer ratio. In the villages where the transfer ratios were high, the abandonment ratios were generally low, demonstrating that the land leasing market has the effect of increasing the utilization rates of farmland resources.

(4) As the occurrence of farmland abandonment in mountainous regions is still affected by the progress of marketization, improving the land leasing market will help prevent farmland, especially that with good farming conditions, from being left uncultivated. When the transfer ratios of farmland were over $20 \%$, the abandonment ratios of farmland at Levels I and II was $6.47 \%$ and $6.92 \%$, respectively. However, the market is still ineffective in preventing the abandonment of farmland with harsh farming conditions. In a larger sense, the abandonment of inferior farmland by the market is conducive to the restoration of the degraded farmland as well as the ecological integrity in mountainous regions. 


\section{References}

Burgess R, 2001. Land and welfare, theory and evidence from China. Working Paper, London School of Economics.

Deininger K, Jin S, 2005. The potential of land rental markets in the process of economic development: Evidence from China. Journal of Development Economics, 78(1): 241-270.

Ge Lin, Gao Ming, Hu Zhengfeng et al., 2012. Reasons of cultivated land abandonment in mountainous area based on farmers' perspective. Chinese Journal of Agricultural Resources and Regional Planning, 33(4): 42-46. (in Chinese)

Guan Yan, 2011. Analysis on market for transferring rural land by transaction cost economics. Economic Problems, (4): 17-20. (in Chinese)

Hou Jian, Fu Bojie, Liu Yu et al., 2014. Ecological and hydrological response of farmlands abandoned for different lengths of time: Evidence from the loess hill slope of China. Global and Planetary Change, 113: 59-67.

Li Zanhong, Yan Jianzhong, Hua Xiaobo et al., 2014. Factors influencing the cultivated land abandonment of households of different types: A case study of 12 typical villages in Chongqing Municipality. Geographical Research, 33(4): 721-734. (in Chinese)

Lin Ruirui, Zhu Daolin, 2014. A spatial and temporal analysis on land incremental values coupled with land rights in China. Habitat International, 44: 168-176.

Liu Yansui, Yang Ren, Long Hualou et al., 2014. Implications of land-use change in rural China: A case study of Yucheng, Shandong province. Land Use Policy, 40: 111-118.

Long Hualou, Liu Yongqiang, Hou Xuegang et al., 2014. Effects of land use transitions due to rapid urbanization on ecosystem services: Implications for urban planning in the new developing area of China. Habitat International, 44: 536-544.

Long Hualou, Zou Jian, Pykett J et al., 2011. Analysis of rural transformation development in China since the turn of the new millennium. Applied Geography, 31(3): 1094-1105.

Milenov P, Vassilev V, Vassileva A et al., 2014. Monitoring of the risk of farmland abandonment as an efficient tool to assess the environmental and socio-economic impact of the Common Agriculture Policy. International Journal of Applied Earth Observation and Geoinformation, 32: 218-227.

Mullan K, Grosjean P, Kontoleon A, 2011. Land tenure arrangements and rural-urban migration in China. World Development, 39(1): 123-133.

Pueyo Y, Beguería S, 2007. Modelling the rate of secondary succession after farmland abandonment in a Mediterranean mountain area. Landscape and Urban Planning, 83(4): 245-254.

Seeborg M C, Jin Z, Zhu Y, 2000. The new rural-urban labor mobility in China: Causes and implications. Journal of Socio-Economics, 29: 39-56.

Shang Xin, Guo Qinghai, 2010. Analysis of behaviors of part-time peasant household based on rational economic man hypothesis. Journal of Jilin Agricultural University, 32(5): 597-602. (in Chinese)

Shao Jing'an, Wei Chaofu, Xie Deti, 2007. Farmers' explanations of land transfer under the household responsibility system: The results from seven villages' analysis in Chongqing. Geographical Research, 26 (2): 275-286. (in Chinese)

Shao Jing'an, Zhang Shichao, Li Xiubin, 2014. Farmland marginalization in the mountainous areas: Characteristics, influencing factors and policy implications. Journal of Geographical Sciences, 25(6): 701-722.

Sklenicka P, Janovska V, Salek M et al., 2014. The farmland rental paradox: Extreme land ownership fragmentation as a new form of land degradation. Land Use Policy, 38: 587-593.

Sluiter R, de Jong S M, 2007. Spatial patterns of Mediterranean land abandonment and related land cover transitions. Landscape Ecology, 22(4): 559-576.

Yao Y, 2007. The Chinese land tenure system: Practice and perspectives. In: Gulati A, Fan S (eds.). The Dragon and the Elephant: Agricultural and Rural Reforms in China and India. Baltimore: The Johns Hopkins University Press.

Ye Jianping, Jiang Yan, Feng Lei, 2006. Investigation of Chinese rural land circulation market: The analysis and suggestions based on the investigation of seventeen provinces in 2005. China Rural Survey, (4): 48-55. (in Chinese)

Yu Qiangyi, Wu Wenbin, Verburg P H et al., 2013. A survey-based exploration of land-system dynamics in an agricultural region of Northeast China. Agricultural Systems, 121: 106-116.

Zaragozí B, Rabasa A, Rodríguez-Sala J J et al., 2012. Modelling farmland abandonment: A study combining GIS and data mining techniques. Agriculture, Ecosystems \& Environment, 155: 124-132.

Zhang Weiwen, Wang Wen, Li Xuewen et al., 2014. Economic development and farmland protection: An assessment of rewarded land conversion quotas trading in Zhejiang, China. Land Use Policy, 38: 467-476.

Zhang Ying, Li Xiubin, Song Wei, 2014. Determinants of cropland abandonment at the parcel, household and village levels in mountain areas of China: A multi-level analysis. Land Use Policy, 41: 186-192. 